\title{
Validity of Note-taking for New Consecutive Interpreting Learners: An Empirical Study of University Interpretation Courses
}

\author{
Hiroko Yamada \\ Kansaigaidai College, Osaka, Japan
}

\begin{abstract}
There is a large body of literature on the subject of note-taking in the field of consecutive interpreting (CI). However, there is a lack of consensus regarding the validity of note-taking during short CI. For one thing, note-taking can divert an interpreter's attention from listening, often to the detriment of analysis. This research empirically studied the effects of intensive interpreting treatment administered to Japanese university students. It then investigated the validity of note-taking for new learners by examining their CI with or without note status, according to language direction from L2 (English) to L1 (Japanese), and vice versa. The results showed a salient link between the treatment's efficacy and the frequency of its administration but did not validate note-taking's usefulness in CI for student interpreters. To further ascertain the validity of notation, CI was also analyzed according to sequentially presented paragraphs.
\end{abstract}

Index Terms - consecutive interpreting, note-taking, validity, frequency, duration

\section{INTRODUCTION}

Consecutive interpreting (CI) is defined as the process of interpretation after a speaker or signer has relayed one or more ideas in the source language and pauses while the interpreter transmits the information (Russell 2005). When interpreting lengthy passages or entire speeches (long consecutive), interpreters use systematic note-taking. For short passages, ranging from one word to a few sentences, or for a bidirectional mode in a dialogue interpreting constellation (short consecutive), CI can be performed with or without notes, as arbitrarily decided by an individual interpreter (Pöchhacker 2016; Russell \& Takeda 2015).

Notes are generally acknowledged as a priority, capable of facilitating the smooth delivery of teacher and student interpretation alike in professional and academic arenas. Note-taking is considered a memory-supporting technique that involves the reception and production of a notation text; such cognitive text processing builds coherence and constructs a mental representation (Albl-Mikasa 2008). A sound note-taking system helps an interpreter analyze the source speech, and strong analysis utilizing notes promotes effective short-term memory operations (Gillies 2017). A large body of literature has explicated and demonstrated this hallmark feature of note-taking (Albl-Mikasa 2006; Dam 2004; Gile 2001; Rozan 1956). Professional interpreters have developed their own note-taking techniques for CI when they are required to render an entire speech. Understandably, when interpreters teach CI in schools, they provide training sessions on note-taking based on their real-life experiences.

Meanwhile, some literature on CI teaching has countered the well-established beliefs about the importance of note-taking. Such studies have examined the effects of note-taking exercises, especially in the first phase of CI, warning of the dangers of excessive notation (Mead 2002, 2011; Seleskovitch 2002; Thiéry 1981). Gile (2009) suggested that note-taking takes away some of the processing capacity available for listening. In fact, especially for undergraduate-level interpreting, recovering meaning from a highly fragmented notation text in $\mathrm{CI}$ is a challenging task that may be detrimental to listening and analysis.

Furthermore, regarding interpreting delivery, when student interpreters take copious notes, their performance often becomes more of a reading and deciphering process than one of speaking (Schweda-Nicholson 1985). Nonetheless, new learners inherit note-taking techniques from their mentors to afford greater security in memory. Sometimes, untrained instructors train students in note-taking to such an extent that it comes to resemble exercises in dictation or shorthand. However, not knowing effective notation methods may have a detrimental effect on students' CI performance, which in turn may discourage them from developing further training or becoming professional interpreters.

In this context, this study empirically examined the effects of English/Japanese CI activities on university students' listening comprehension and interpreting ability. Then, the study explored how note-taking may or may not make cognitive text processing more efficient for student interpreters in the reformulation phase. First, the study examined the efficacy of CI treatment using various approaches in two introductory interpreting classes at a Japanese university during the 2017 fall semester. Comparative analysis was conducted to explicate the effects of treatments employed with differing frequencies and durations per lesson during the administration period according to language direction-namely, interpreting from L2 to L1 and from L1 to L2. The main question concerned how best to deploy CI activities during a semester to maximize the efficacy of university training sessions. Next, the validity of CI note-taking 
was addressed. Specifically, the secondary aim of this study was to realistically assess the effectiveness of note-taking. Students' interpreting abilities were tested as they listened to identical source texts on two different task statuses-namely, consulting notes and not consulting notes. Students' bidirectional CI skills were then assessed to investigate the effect of notation on their processing capacity according to language direction.

It is generally recognized that interpreter training should be introduced in the consecutive mode, initially based on memory, before gradually incorporating note-taking (Pöchhacker 2016). However, when and how note-taking training should proceed remains open to discussion. The critical nature of note-taking is always the focus of classroom experiments (Gile 1991) and note-taking is a primary topic in CI teaching and research (Russell \& Takeda 2015). Nevertheless, few studies have empirically analyzed the legitimacy and justification of notation exercises administered to student interpreters. This provided a point of departure for the present study. This study aimed to shed light on the act of note-taking, which involves highly intricate cognitive processing and thus entails a great risk of interpreting error.

\section{BACKGROUND}

In recent decades, university student interest in interpreter training has remained high; however, Japanese universities tend to focus on enhancing students' language abilities as opposed to developing and fostering interpreters (Komatsu 2017). The main reason for this is insufficient L2 proficiency (usually in English) at the undergraduate level (Komatsu 2017). According to a multiple-choice survey conducted by the Japan International Cooperation Center (JAIS) in 2007 concerning the objectives of interpreter training programs in Japanese universities, 80\% of respondents (total: 377) chose "to enhance English proficiency" as the objective while only $45 \%$ of students chose "to study interpreting." In recent years, this trend toward prioritizing language learning has been reinforced (Komatsu 2017). Komatsu (2012) suggested that interpreter training methods could help improve learners' language proficiency if university programs were to adopt interpreter training methods. However, few studies have empirically analyzed the effects of Japanese university interpreter training programs on students' language proficiencies and CI skills as they develop throughout a course. The present study, therefore, first examined the efficacy of interpreter training to gauge whether it enhanced students' language proficiency (namely, in listening comprehension and interpreting abilities). In particular, it analyzed the effects of CI treatment based on the frequency and duration of administration; one treatment was condensed while the other was scattered over the semester.

More importantly, this study investigated the validity of note-taking during CI. Interpreters generally rely on a combination of notes, memory, and general knowledge to recreate original speech. Notes represent the skeleton structure of the original speech or a group of ideas in a particular order as opposed to an arbitrary muddle of unrelated ideas (Gillies 2017). In this sense, interpreters' notes are a visual representation of their source speech analysis (Gillies 2017). To date, professional interpreters and scholars - including Seleskovitch (1984, 1988, 2002), Thiéry (1981), Gran and Dodds (1989), Matyssek (1989), Dam (2004), Gillies (2001, 2017), and others - have pursued systematic methods of note-taking that support memory and source language speech retrieval to facilitate an accurate rendition in the target language. On the subject of note-taking, Rozan's (1956) system is considered "classic," having influenced and been incorporated into all methods of note-taking.

Many scholars, however, warn of the pitfalls of focusing too much on note-taking. Gile (2009) noted that manual note-taking requires more time than speech production; hand movements are slow and thus produce a lag, which puts more pressure on the short-term memory and reduces the capacity for listening and analysis. Thiéry (1981) argued that notes should be taken as few as possible and should only provide a platform or safety net for confident delivery. Albl-Mikasa (2017) cautioned that interpreters have sought to find means of focusing on source messages through the "language-independent nature of notation," regardless of the working language involved. In response to such negative views of notation, a large body of research has aimed to demonstrate the importance of capturing the sense or ideas of source-language (SL) messages while taking notes, exploring how notes should be taken without resorting to verbatim interpreting.

The degree to which an interpreter resorts to note-taking depends on several factors, including the length of the speaker's utterance and the interpreter's physical constraints and memory (Russell \& Takeda 2015). However, we can assume that if the effort invested in note-taking is reduced as much as possible - since taking notes can divert attention from listening (e.g., Gile 2009; Thiéry 1981) — an interpreter is likely to perform better CI. If the effort required for note-taking were reduced to zero, how would it affect an interpreter, especially one who is a student who has difficulty using note-taking as a tool for CI? This question provided the motivation for the present empirical study. Thus, the research questions were formulated as presented in the next section.

\section{RESEARCH QUESTIONS}

1) Would intensive CI training have varied effects on university students' CI abilities and overall listening comprehension abilities if administered to two groups of university students over the same time span with differing frequencies and durations per lesson?

2) Could note-taking possibly render text processing more efficient for new CI learners? 


\section{METHOD}

\section{A. Research Participants}

This research was conducted in the fall semester of 2017 at a Japanese university where the researcher teaches. The participants were divided into two groups. Class 1 attended two English/Japanese interpreting lessons for one and a half hours per week for a total of 30 lessons in the semester. Class 2 students had 15 three-hour lessons held once a week over the course of the same semester. Each class covered equivalent amounts of time as the treatments were administered. There were 18 students in class 1 and 17 in class 2. All were third- and fourth-year English majors enrolled in an introductory English-to-Japanese interpreting course. None of the students had received prior interpreter training.

\section{B. Procedures}

All lessons were taught in the CALL (computer-assisted language learning) room, and the interpreting activities were taken from interpreting studies textbooks for beginners. The same procedures and materials were used for classes 1 and 2. The researcher's instructions on how to take notes followed the principles described in Gillies (2017):

1) Learning to break down speech into ideas

2) Noting the subject, verb, and object across the page diagonally to understand the structure clearly at a glance

3) Introducing links that reveal how two ideas fit together

4) Identifying verticality and hierarchies of value

5) Using symbols

6) Noting less to leave room for ideas to stand out on the page

Training was conducted in CI from L2 to L1 (English to Japanese) and from L1 to L2 (Japanese to English). CI training activities where students were either allowed or not allowed to take notes involved the same procedures, applied in the following order:

1) Listening

Students listened to the SL text once with the textbook closed to learn the text's outline.

2) Shadowing, repeating, retention, and sight translation

Students performed the abovementioned interpretation-related tasks selected according to the intelligibility of the source text to prepare for CI.

3) Oral representation as rehearsal and monitoring

Students were asked to listen to up to four SL sentences at a time with the textbook closed. They were then instructed to interpret the sentences together verbally in the target language (TL) using microphones attached to their headsets. Each student's performance was monitored by the researcher, and instructions were given to certain students when necessary. Such interactions could only be heard by the student and the researcher.

4) Oral representation on a real stage

A student was then selected to perform a complete consecutive TL interpreting of the message he or she had listened to in step three. This performance was heard not only by the researcher but also by the other students.

5) Recording individual students' performance

To identify specific causes of interpreting problems, students were asked to record their CI performances on their computers and listen to them carefully with the source text open to develop strategies for solving specific processing problems. Recordings of their performances were repeated several times to improve their performance quality.

\section{Data Collection}

Data were collected on two occasions: the midterm examinations after $15^{\text {th }}$ and $7^{\text {th }}$ lessons for classes 1 and 2 , respectively, and the final examinations after the $30^{\text {th }}$ and $15^{\text {th }}$ lessons for classes 1 and 2 , respectively. Verbal interpreting performances were recorded on each student's computer before they were all copied to a USB flash drive and assessed by the researcher. The study design was approved by the university review board. The researcher obtained written consent from the students to use the test results as data.

\section{Materials}

The test items comprised material that the students had never attempted before. Excerpts from the final exam items are provided below. The English SL text comprised a total of 237 words, and the Japanese SL text had 502 letters. Each text was organized into six paragraphs; the students heard each paragraph and interpreted it into the TL soon after.

English text test example:

Paragraph One

On April 26, 2011, Donald Keene, an 88-year-old renowned expert in Japanese literature and culture, gave his last lecture at Columbia University in which he announced that he would be leaving the United States in order to spend the rest of his life in Japan (Tomono, Miyamoto \& Minamitsu 2012).

An example of the test items in the Japanese text:

Paragraph 6

しかし私たちは楽しく心躍る想い出を胸に持ってお別れします。そしてこの別れは一時的なものである 
ことを承知しています。またすぐ帰ってくることができます。そちらからも、いつでも私たちのところに来 ることができます。(But we say sayonara with happy and exciting memories. And we know that this parting is only temporary. We can come back soon, and you can visit us anytime.) (Mukai, Maruyama \& Matsuoka 2004)

\section{E. Measurement}

First, pre- and posttests were conducted to examine students' development of overall listening comprehension abilities. The pretests were implemented during the first lesson of the semester, and posttests were carried out in the respective final lessons of classes 1 and 2. The test was a simplified version of the TOEIC: 100 standard TOEIC listening questions were reduced to 50. The marks obtained on the TOEIC test were analyzed using $\mathrm{F}$ and $\mathrm{T}$ tests. To measure the CI treatment's direct effect on CI technique, the researcher first compared CI marks for L2 to L1 between the two classes on the midterm examinations. A final examination was implemented after the completion of all lessons, and the total marks obtained in CI from L2 (English) to L1 (Japanese) and L1 (Japanese) to L2 (English) were analyzed, and classes 1 and 2 were compared. The second research question regarding note-taking's validity in CI was then investigated. The final examination results were analyzed according to two different variables-namely, with and without notes, in classes 1 and 2, respectively. Finally, to further ascertain the legitimacy of note-taking for new learners, a more minute analysis was employed in which the circumstantial validity of notation was examined by analyzing CI according to sequentially presented paragraphs. Each paragraph was numbered from one to six in the order students listened to them in the respective cases of L2 to L1 and L1 to L2 interpreting. Students listened to identical test items in two separate trials. In the first trial, the first half did not take notes while the latter half did, and vice versa in the second trial. For more precise explication, the procedures are presented in Table 1.

TABLE 1

TEST PROCEDURES TAKEN BY L2 TO L1, AND L1 TO L2 CI, RESPECTIVELY, IN THE FINAL EXAMINATION.

\begin{tabular}{lllllll}
\hline & Paragraph 1 & Paragraph 2 & Paragraph 3 & Paragraph 4 & Paragraph 5 & Paragraph 6 \\
\hline First trial & Without notes & Without notes & Without notes & With notes & With notes & With notes \\
\hline Second trial & With notes & With notes & With notes & Without notes & Without notes & Without notes \\
\hline \multicolumn{7}{c}{ Note: full marks equal 10 points per paragraph for each trial. }
\end{tabular}

Further, to reduce the practice effect, the final examination included test items between the first and second trials that were irrelevant to the present research. This addressed the issue of first-trial performances influencing the second trial. The CI recording lasted a total of 70 minutes, including 40 minutes used specifically for the present research and 30 minutes for test items irrelevant to this research.

Concerning point allocation, full marks equaled 10 points per paragraph; that is, regarding CI without notes, 30 points from paragraphs one to three from the first trial were added to 30 points from paragraphs four to six in the second trial, totaling 60 points for the six paragraphs. Similarly, with respect to CI with notes, 30 points from paragraphs four to six in the first trial were added to 30 points from paragraphs one to three in the second trial, totaling 60 points for the six paragraphs. The same allocation was adopted for CIs from L1 to L2 and from L2 to L1, both of which were rated for classes 1 and 2, respectively, and then compared.

Regarding the assessment criteria, CI performances in two directions - from L2 to L1 and L1 to L2 - were analyzed using Viaggio's (1995) criteria:

1) Comprehension: Has the student understood everything correctly?

2) Reexpression: Did the student make syntactic or lexical mistakes?

3) Style: Could it have been expressed better?

More specifically, according to each phrase or semantic chunk, recorded performances were assessed in detail based on a scoring rubric devised by the researcher (Yamada 2015). In the scoring rubric, specific points were allocated according to the difficulty level of translating each semantic chunk or phrase. To ascertain a specific word's difficulty level, a "word frequency list" from an academic area was used (http://www.wordandphrase.info/frequencyList.asp). The total marks were calculated and analyzed using $\mathrm{T}$ and $\mathrm{F}$ tests.

\section{REsults}

\section{A. Quantitative Analysis}

TABLE 2

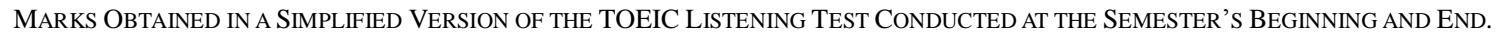

\begin{tabular}{|c|c|c|c|c|}
\hline Pretest & & & & \\
\hline & $\mathrm{N}$ & Mean & SD & $t$ \\
\hline TOEIC Class 1 & 18 & 38.78 & 6.26 & -1.13 \\
\hline TOEIC Class 2 & 17 & 36.59 & 5.1 & -1.13 \\
\hline \multicolumn{5}{|l|}{ Posttest } \\
\hline & $\mathrm{N}$ & Mean & SD & $t$ \\
\hline TOEIC Class 1 & 18 & 40.39 & 5.23 & -2.30 \\
\hline TOEIC Class 2 & 17 & 35.94 & 6.18 & -2.30 \\
\hline
\end{tabular}


As shown in Table 2, when class 1's and 2's English listening comprehension marks were compared at the beginning of the semester, the difference between them was insignificant $(p=.27)$, which shows that the students' listening comprehension abilities were almost the same prior to CI treatment. However, marks obtained at the end of the semester yielded statistical differences between the classes $(p<.05)$. Class 1 scored significantly higher than class 2 . This suggests that treatment of CI, when administered with more frequency but less duration per lesson, may work more effectively on listening comprehension development than more condensed, less frequent treatments.

Next, the effects of treatment on CI skills were investigated, and the results of the midterm examination are shown in Table 3.

TABLE 3

MARKS OBTAINED IN CI FROM L2 TO L1 IN CLASS 1 AND 2 IN THE MIDTERM EXAMINATIONS.

\begin{tabular}{lcccl}
\hline & $\mathrm{N}$ & Mean & $\mathrm{SD}$ & $t$ \\
\hline CI Class 1 & 18 & 18.72 & 8.06 & -1.38 \\
\hline CI Class 2 & 17 & 15.24 & 6.72 & -1.38 \\
\hline
\end{tabular}

Note: full marks equal 30 points.

As Table 3 shows, class 1 slightly outperformed class 2 in midsemester CI performance. However, the difference between classes was not statistically significant.

In the next phase, final examination results of classes 1 and 2 were compared. The results are shown in Table 4.

TABLE 4

TOTAL CI MARKS FROM L2 TO L1, AND L1 TO L2 COMBINED IN CLASS 1 AND 2 IN THE FINAL EXAMINATIONS.

\begin{tabular}{lllll}
\hline & $\mathrm{N}$ & Mean & SD & $t$ \\
\hline CI Class 1 & 18 & 146.5 & 41.57 & -2.45 \\
\hline CI Class 2 & 17 & 109.70 & 47.28 & -2.45 \\
\hline \multicolumn{5}{c}{ Note: ${ }^{*} p<.05 ;$ full marks equal 240 points. }
\end{tabular}

As Table 4 shows, class 1 outperformed class 2, and the differences between the two classes' bidirectional CI (combined scores from L2 to L1 and L1 to L2) were significant ( $p=.02, * p<.05)$. As mentioned earlier, the midterm examinations did not show statistically significant differences between the classes whereas the final examinations did. This suggests that CI treatment worked on class 1 students' performance more effectively over time. Turning to standard deviation, class 2's value is higher than that of class 1, revealing that individual students' CI performance accuracy was less standardized in class 2 . The measurement models indicated that class 2 students' CI performances varied more in quality and were generally lower than class 1 students.

Next, marks obtained with and without notes are compared and shown in Table 5.

TABLE 5

COMPARISON OF CI MARKS OBTAINED WITH AND WITHOUT NOTES IN COMBINED FIRST AND SECOND TRIALS.

\begin{tabular}{|c|c|c|c|c|c|}
\hline \multicolumn{6}{|c|}{ CI from $\mathrm{L} 2$ to $\mathrm{L} 1$} \\
\hline & & Availability of notes & $\mathrm{N}$ & Mean & $t$ \\
\hline \multirow{2}{*}{$\begin{array}{l}\text { Class } 1 . \\
\text { to J }\end{array}$} & \multirow[t]{2}{*}{ CI from $\mathrm{E}$} & Without notes & 18 & 4.47 & \multirow[t]{2}{*}{0.60} \\
\hline & & With notes & 18 & 4.3 & \\
\hline \multirow{2}{*}{$\begin{array}{l}\text { Class } 2 . \\
\text { to } \mathrm{J}\end{array}$} & \multirow[t]{2}{*}{$\mathrm{CI}$ from $\mathrm{E}$} & Without notes & 17 & 3.02 & \multirow[t]{2}{*}{-0.88} \\
\hline & & With notes & 17 & 3.29 & \\
\hline \multicolumn{6}{|c|}{$\mathrm{CI}$ from L1 to L2 } \\
\hline & & Availability of notes & $\mathrm{N}$ & Mean & $\mathrm{t}$ \\
\hline \multirow{2}{*}{$\begin{array}{l}\text { Class } 1 . \\
\text { E }\end{array}$} & \multirow[t]{2}{*}{$\mathrm{CI}$ from $\mathrm{J}$ to } & Without notes & 18 & 7.53 & \multirow[t]{2}{*}{-1.36} \\
\hline & & With notes & 18 & 7.72 & \\
\hline \multirow{2}{*}{$\begin{array}{l}\text { Class } 2 . \\
\text { E }\end{array}$} & \multirow{2}{*}{ CI from $\mathrm{J}$ to } & Without notes & 17 & 5.80 & \multirow[t]{2}{*}{-1.66} \\
\hline & & With notes & 17 & 6.16 & \\
\hline
\end{tabular}

Notes: full marks equal 10 per paragraph. CI from E to J: consecutive English to Japanese interpreting. CI from J to E: consecutive Japanese to English interpreting.

When analyzing this data with $\mathrm{T}$ and $\mathrm{F}$ tests, from L2 to L1, no statistical differences between CI with and without notes were observed for class 1 or class 2 ( $p=.55$ for class $1, p=.38$ for class 2 ). Similarly, in L1 to L2, no significant differences between CI with and without notes were found in class 1 or class 2 ( $p=.18$ for class $1, p=.10$ for class 2 ). In summary, the results suggest that the availability of notes does not have a serious effect on students' bidirectional CI performance.

Next, paragraph-by-paragraph scrutiny was conducted according to sequentially presented paragraphs for class 1 , who performed better than class 2 , to further investigate the effects of note-taking. The final examination results of CI are shown in Table 6. 
TABLE 6

CI PERformance ACCORding to SEQUENTIALly PRESENTEd PARAGRAPHS With AND Without Note-TAKING IN THE COMBINED FIRST AND SECOND TRIALS OF CLASS 1

\begin{tabular}{llllll}
\hline From English (L2) to Japanese (L1) CI & & & & \\
\hline Paragraph number & Availability of notes & N & Mean & SD & $t$ \\
\hline 1 & Without & 18 & 3.72 & 3.14 & -2.12 \\
& With & 18 & 4.44 & 2.91 & \\
\hline 2 & Without & 18 & 3.78 & 2.92 & -2.67 \\
& With & 18 & 4.94 & 2.88 & \\
\hline 3 & Without & 18 & 4.5 & 3.03 & -2.06 \\
& With & 18 & 5.5 & 3.22 & \\
\hline 4 & Without & 18 & 2.89 & 2.87 & -0.45 \\
& With & 18 & 2.72 & 2.61 & \\
\hline 5 & Without & 18 & 7.94 & 2.15 & -4.68 \\
& With & 18 & 5.72 & 2.22 & \\
\hline 6 & Without & 18 & 4 & 2.81 & -2.77 \\
& With & 18 & 2.44 & 2.50 &
\end{tabular}

Note: paragraph 1: $* p<.05 ;$ paragraph $2: * p<.05 ;$ paragraph $5: * * * p<.001$ paragraph $6: * p<.05$. Full marks equal 10 points per paragraph.

\begin{tabular}{llllll}
\hline From Japanese (L1) to English (L2) CI & & & & \\
\hline Paragraph number & Availability of notes & $\mathrm{N}$ & Mean & SD & $t$ \\
\hline 1 & Without & 18 & 6.56 & 2.28 & -4.27 \\
& With & 18 & 8.39 & 1.54 & \\
\hline 2 & Without & 18 & 8.61 & 1.29 & -2.61 \\
& With & 18 & 9.39 & 1.97 & \\
\hline 3 & Without & 18 & 6.72 & 2.22 & -3.82 \\
& With & 18 & 7.89 & 1.97 & \\
\hline 4 & Without & 18 & 7 & 1.97 & 0.33 \\
& With & 18 & 7.11 & 1.91 & \\
\hline 5 & Without & 18 & 8.5 & 1.97 & -0.42 \\
& With & 18 & 8.33 & 1.78 & \\
\hline 6 & Without & 18 & 7.78 & 1.86 & -0.5 \\
& With & 18 & 7.61 & 1.72 & \\
\hline Note: paragraph 1: $* * * p<.00 ;$ paragraph $2: * p<.05 ;$ paragraph $3: * * p<.01$. \\
& Full marks equal 10 points per paragraph. & &
\end{tabular}

As shown here, the CI results from L2 to L1 and L1 to L2 are mixed. In the first two paragraphs from L2 to L1, the mean CI values were higher when notes were taken than when notes were not taken. This shows a statistical difference between the two statuses (paragraph 1: * $p<.05$, paragraph $2: * p<.05$ ). Meanwhile, regarding paragraphs five and six, CI without note consultation outperformed with-note consultation; here, they yielded a significant difference (paragraph 5: $* * * p<.001$, paragraph $6: * p<.05$ ). However, in the middle of the speech-namely, between the third and fourth paragraphs - no statistical difference was found between the two conditions. This finding suggests that CI performance from L2 to L1 is better with notes in the earlier stages of interpreting performance; however, as CI progresses, interpreting without note consultation outperforms CI with note consultation.

Interestingly, L1 to L2 CI yielded different results than L2 to L1. For the first three paragraphs, mean CI values were higher when notes were taken than when notes were not taken. Here, a significant statistical difference is shown (paragraph 1: $* * * p<.001$, paragraph $2: * p<.05$, paragraph $3: * * p<.01$ ). However, the last three paragraphs show no significant difference between the with-note and without-note statuses. This indicates that CI from L1 to L2 is better with taking notes than without taking notes in the earlier stage of the SL speech. However, as CI gets underway in the later stage of the speech, the availability of notes is no longer a critical issue for student interpreters.

\section{B. Qualitative Analysis}

1. Processing problems and strategies

Students adopted several basic strategies to reach an editorially acceptable translation. Student processing problems were classified into the following six categories using Ivanova's (1999) criteria: 1) syntactic processing, 2) text integration, 3) text retrieval, 4) equivalence, 5) lexical access, and 6) TL delays. They were analyzed by presenting examples of student strategies

Regarding CI from L2 to L1, the most frequent problems were associated with syntactic processing and text integration. Some students failed to recognize syntax, which was induced by an inability to identify verbs; thus, they were unable to construct coherent representations for an SL chunk. Notwithstanding the researcher's instruction to take notes on subject, verb, and object units across the page diagonally (see 4.2.), students were unable to separate words into units upon hearing them successively. Failure to identify which semantic chunk should be included in a subject or predicate clause may stem from students' fundamental syntactic processing inabilities. Since verbs are fundamental to understanding speech, verb identification is critical for processing syntax and properly integrating it into TL texts. Nonetheless, $\mathrm{S}+\mathrm{V}+\mathrm{O}$ analysis failure was often observed among students when they encountered difficult syntactic structures. 
Numerical items embedded in sentences may also be responsible for students' translation departures. Since the beginning of the sentence included three numbers - namely, "April 26," "2011," and "88-year-old"-it was extremely difficult for students to accurately interpret numerical information by listening only once. It could be that students were distracted by these numbers to such a degree that they were unable to focus on verb identification. This would be consistent with Gile's (2009) claim that writing down numbers and names costs time since writing is slow. As such, note-taking increases the risk of losing other information that comes before and after information that is written down. Regarding numbers, the researcher intentionally selected an SL text in which several numerical items were embedded to assess the students' ability to respond to numbers quickly and speak them accurately in the TL. Again, different task statuses were implemented involving consulting and not consulting notes. The findings showed that upon hearing SL texts, students were equally unable to jot down correct numbers on the spot and translate them into the TL, regardless of whether they were allowed to take notes. In other words, students could not interpret numbers regardless of note-taking status.

Further, capturing verb tense and modal verbs was a problem for most students, whose confusion regarding tense induced a failure to construct an accurate chronological order of events. Throughout the six paragraphs, frequent disruptions in delivery were prompted by an inability to identify verb tense, resulting in students' failure to coherently integrate the texts. Even then, some students adopted strategies to employ creative translations to compensate for their ineptitude. These students tried to integrate disrupted interpretations into the text by guessing tenses based on context.

Regarding text retrieval, here is an excerpt from paragraph three: "On June 13, / Keene gave / what he called / 'the last lecture in New York' / at the Japan Society / where he again announced / that he would be leaving the US for Japan / in order to become a Japanese citizen." Since the sentence has several semantic chunks, many students failed to retrieve all pieces of information, syntactically understand them, and determine a plausible TL text. As Dillinger (1994) noted regarding the effect of textual structure on an interpreter's comprehension, propositional density in syntactic environments, such as clause density and clause embedding, negatively affects interpretation accuracy. Students had difficulty understanding complex clause structures and processing syntax upon a single hearing. Students' failure to recognize relative importance to honor the hierarchy of main ideas (Jones 1998) may be also responsible for translation disruption.

Regarding equivalence, some students failed to produce an automatic equivalent since it was difficult to select the appropriate one when given several choices. Here is a section of paragraph two, for example: "This announcement came as a surprise since many foreigners were actually leaving Japan, especially after the 3/11 earthquake and tsunami and subsequent radiation from the damaged nuclear reactor." Students clearly understood the meaning of the underlined phrase because it was familiar to them as Japanese people. Nonetheless, most students were unable to find an automatic equivalent and produce a proper Japanese translation for this phrase. In this case, some students may have employed a strategy of compromise - namely, lowering the acceptability standards for TL production (Ivanova 1999) and creating an editorially acceptable phrase based on their previous knowledge.

Regarding lexical access, most students wrote down proper nouns, though some wrote down unknown words and later stumbled over them. Examples of such words and phrases included "Japan society," "Nazi troop," "Japanologist," and "The Tale of Genji." Upon translating these words, students sometimes paused or stopped speaking, resulting in TL delays. During such delays, students inferred words' meanings from the context and, in some cases, invented translations for them. When students recognized TL delays, they employed strategies such as omission, overgeneralization, or excessive paraphrasing by selecting more abstract and less specific representations to compensate for the delay.

Thus far, processing problems and strategies occurring in CI from L2 to L1 have been discussed. When investigating L1 to L2 interpreting, it was found that students performed better by naturally adopting strategies. Students were likely to reformulate syntactically difficult SL Japanese sentences into easy TL English instead of employing literal translations. Mead (2002) suggested that formulation (the effort exerted to formulate sentences) is the main cause of student hesitation. However, there was no hesitation among students as they reformulated complex L1 sentences into simple L2 sentences. For example, when encountering syntactically difficult structures such as “さて一つ皆さんが変 えたらいいな、と思うことがあります” (“Well, there is one thing you could change”), they may have employed the strategy of compromise by just saying, "You should change something." It was inferred that this conversion would be possible because the SL was their first language; therefore, they may have processed the syntactically difficult SL phrase into simple TL syntax instantaneously on the cognitive level.

\section{DISCUSSION}

\section{A. Testing Research Question One}

For the present research, CI training was administered to two classes using a different approach for each. Treatments were applied to class 1 with more frequency but less duration per lesson while more concentrated but less frequent activities were employed in class 2; both covered equivalent spans of administration time. The semester-long period was initially assumed not to be sufficient for identifying appreciable differences in the listening comprehension and interpreting abilities of students in the two classes. Nonetheless, the TOEIC posttest results showed statistical 
differences between the classes: class 1 scored significantly higher than class 2, even though the pretest showed no statistical difference between them. Similarly, regarding CI in the final examination, class 1 obtained significantly higher marks than class 2, whereas the midterm examinations did not yield statistical differences between them. These findings suggest that CI lessons employed in university curricula may enhance students' listening comprehension and interpreting abilities if they are repeated frequently and regularly throughout the semester, notwithstanding relatively shorter durations per lesson. Meanwhile, condensed, less frequent lessons deployed over a semester may not be an effective methodology for introductory university CI programs.

CI is a multitasking action. Dam (1993) divided CI into two phases: reception (where the interpreter listens to original speech) and production (where the interpreter delivers the speech in another language). Jones (1998), meanwhile, divided CI into four phases: listening, understanding, analyzing, and reexpressing. The findings of the present study indicated that CI activities are likely to work gradually over time, increasing students' multitasking capacities only if the treatments are administered frequently. Viewed from a different angle, working memory capacity may be a useful tool for explaining the importance of a treatment's frequency. Working memory (WM) is mechanism or process in the service of complex cognition that is involved in the control, regulation, and active maintenance of task-relevant information (Baddeley 1986; Ericsson 2000; Ito 2017; Miyake 1999). As WM load progressively increases, WM capacity extension follows; hence, deliberate practice in CI allows frequent tasks to be automated, and more WM resources are liberated to better cope with controlled tasks (Ito 2017). We can infer that frequent training provided over the course of a semester may have facilitated gradual increases in students' WM capacities, which led to enhanced overall processing capacities. As a result, the class with more frequent training outperformed the other class.

\section{B. Testing Research Question Two}

This study's second research question was, "Could note-taking possibly render text processing more efficient for new CI learners?" This question has some implications - namely, that there would be no pronounced CI difference between those consulting notes and those not consulting notes. Another possibility is that notes taken during CI would not facilitate cognitive text processing but hinder it. Based on this hypothesis, this study empirically analyzed the legitimacy and justification of note-taking for new CI learners.

No significant difference was found in CI performances with and without notes among student interpreters regardless of language directionality. This may substantiate the findings of Gile (2009), who conducted a similar experimental study, providing CI exercises to two student groups; one group was instructed to take notes while the other was told not to. Students were then asked to indicate whether they heard a name included in the short presentation properly. After replication, it turned out that students who did not take notes "heard" the names better than those who did. Gile explained that note-taking may have taken away some of the processing capacity initially available for listening. Thus, a relevant conclusion might propose that note-taking does not have salient attributes directly facilitating text production in short consecutive interpreting.

To further examine whether note-taking is useful or harmful to new CI learners, paragraph-by-paragraph scrutiny was undertaken to examine how notation effects vary during CI performance based on chronological data. The findings revealed that CI from L2 to L1 was better performed by those who consulted notes than those who did not in the early stages of SL speech, yielding a statistically significant difference between statuses. However, as speech progressed, performance without notes outperformed performance with notes, also showing significant differences between the two. It is inferred that CI required less processing effort as paragraph test items proceeded and students used consistent effort for task completion repeatedly, which left time and capacity exclusively for listening to and understanding the SL message. For the last two paragraphs, processing capacities were more augmented when notes were not available than when they were, since notation requires multitasking.

Regarding the interpreter's increased processing capacity as SL speech progressed, Seleskovitch (2002) explained that during a conference, interpreters often initially note technical terms in the original language. As speech progresses, however, subconscious efforts elicit corresponding words in other languages, and their correct translation becomes a reflex, resulting in noting down technical terms directly in the TL. Note that it is generally acknowledged that taking notes in TL implies that the interpreter can genuinely process incoming information while listening (Rozan 1956; Seleskovitch 2002; Jones 1998).

Interestingly, the findings for L1 to L2 CI differed from those for L2 to L1. For the first three paragraphs, the marks were higher for CI with notes than CI without notes, showing statistical differences between the statuses. However, the final three paragraphs showed no statistical differences between statuses. This indicates that CI with note-taking was better displayed than CI without notes in the first half of the SL speech, whereas when CI began in the speech's latter half, performance did not differ, regardless of the availability of notes. Note-taking is no longer a critical issue for student interpreters. In contrast to the detrimental effects of note-taking in L2 to L1 interpreting, note-taking did not adversely affect its L1 to L2 counterpart. Earlier studies noted that lexical-conceptual links are stronger for L1 words than L2 words, which results in easier mapping between the form and meaning of L1 words than L2 words (Dong, Gui \& MacWhinney 2005; Dong \& Lin 2013; Kroll \& Stewart 1994). In the case of L1 to L2 interpreting, the phase of reformulation activated by form (word by word) may be more easily modulated to meaning than in L2 to L1 (Yamada 2018). It is likely that this feature served to more easily convert the students' verbatim notes into meaning, which resulted in complementing note-taking's negative factors. 
Gile (2009) noted that when processing capacity requirements for listening and analysis efforts are raised, some resources can be freed up by reducing the quantity of notes taken, whereas reducing the amount of information taken in notes does not necessarily lead to an increase in information stored in the short-term memory and later reformulated in the TL. It can be inferred from this that any reduction in note quantity may not impose serious burdens on short-term memory; rather, it may serve to achieve better CI performance. Reducing the quantity of notes is theoretically possible if students are properly trained. As Gillies (2017) suggested, note-taking is a mechanical activity; therefore, by using a consistent method repeatedly, it becomes automatic and internalized. While this idea might be intellectually sound, the main issue is that most university students will not be able to master such skills over the course of a semester.

In practice, CI instructors repeatedly tell students to note ideas, not words (Rozan 1956). This doctrine has been effective for educational purposes, especially for student interpreters who may tend to write down words they hear without understanding their meanings. Other students may understand the meanings of the words or have a vague idea of a phrase's meaning, but they cannot speak it out in the TL. Verbatim notes can perplex students when they interpret SL messages, and their confusion prompts serious disfluency and hesitation in their utterances. Since students are unsure of what is being said, they frantically relate the words they just wrote in the notes into meanings, which may lead to a failure of coherence as they create the TL text. Even if students are sure of what was said and write down specific phrases in their notes, these hastily scribbled notes are not always legible, and the idea they jotted down in the notes eludes them. Thus, the principle of "note down ideas, not words" is difficult to put into practice, especially for new learners. Furthermore, if novice interpreters think too much about how to write something, they will listen less. In fact, is much more common for student interpreters to not hear something than to not understand something (Gilllies 2017). If this is the case, then CI that involves not taking notes but focusing all attention on grasping the sense or the ideas will more likely result in an accurate, confident performance.

The present study revealed that note-taking may not serve as a valuable interpreting tool, regardless of directionality, especially for material comprising paragraphs of some 40 English words, amounting to a duration of no more than half a minute. However, this study provides no further answers as to which factor renders note-taking training introduced in CI lessons valid or invalid. Prioritizing memory-based exercises in analysis and interlingual reexpression before gradually introducing note-taking may provide a starting point for research that could provide fresh insights into the effectiveness of conducting CI with and without notes.

\section{CONCLUSION}

The parameters and interpreting conditions introduced so far concern the ways in which student interpreters perform CI. As such, the crucial distinction between students and more experienced professional interpreters should be considered in terms of the level and expertise with which interpreters perform tasks. Nonetheless, this study has reached certain conclusions relevant to the field of education and training for undergraduate-level interpreters.

First, the findings suggest that more frequent, periodically arranged lessons can more effectively improve students' listening comprehension abilities and CI skills. Second, considering the difficulties students face when relying entirely on notes while performing CI, this study investigated the validity of note-taking for new CI learners. The experiments did not demonstrate the validity of note-taking, save for in a limited CI setting. However, a large-scale study would be required to reach definitive conclusions regarding this matter.

Despite some limitations, this study provides insight into the areas interpreting education should focus on to develop more refined interpreting tools and training programs. Despite the many models and orientations advocated in the field of interpreting pedagogy, a sound method that shows how these models sustain CI skill development has yet to emerge. This study may provide guidance for CI curriculum planning as well as interesting perspectives on CI education at the undergraduate level.

\section{REFERENCES}

[1] Albl-Mikasa, M. (2006). Reduction and expansion in notation texts. In H. Garmen, K. Schubert \& H. Gerzymisch-Arbogast (Eds.), Text and translation: Theory and methodology of translation. Jahrbuch Übersetzen and Dolmetschen. DGÜD. Tübingen: Gunter Narr, 195-214.

[2] Albl-Mikasa, M. (2008). (Non-)Sense in note-taking for consecutive interpreting. Interpreting 10 (2), 197-231.

[3] Albl-Mikasa, M. (2017). A cognitive-linguistic model of consecutive interpreting. InY. Someya Consecutive notetaking and interpreter training. London and New York: Routledge, 71-117.

[4] Baddeley, A. (1986). Working memory. Oxford: Clarendon Press.

[5] Dam, H. V. (1993). Text condensing in consecutive interpreting. In Y. Gambier \& J. Tommola (Eds.), Translation \& Knowledge: SSOTT IV. Turku: University of Turku Press, 297-316.

[6] Dam, H. V. (2004). Interpreters' notes. On the choice of language. Interpreting 6 (1), 3-17.

[7] Dillinger, M. (1994). Comprehension during interpreting: What do interpreters know that bilinguals don't? In S. Lambert \& B. Moser-Mercer (Eds.), Bridging the Gap: Empirical research in simultaneous interpretation. Amsterdam: John Benjamins, 155-189.

[8] Dong, Y. \& Lin, J. (2013). Parallel processing of the target language during source language comprehension in interpreting. Bilingualism: Language and Cognition 16 (3), 682-692.

[9] Dong, Y., Gui, S. \& MacWhinney, B. (2005). Shared and separate meanings in the bilingual mental lexicon. Bilingualism: 
Language and Cognition 8 (3), 221-238.

[10] Ericsson, K. A. (2000). Expertise in interpreting: An expert-performance perspective. Interpreting 5 (2), 187-220.

[11] Gile, D. (1991). Prise de notes et attention en début d'apprentissage del'interprétation consecutive-une expérience-démonstration de sensibilisation. Meta 36 (2), 431-439.

[12] Gile, D. (2001). Consecutive vs. simultaneous: Which is more accurate? Tsuuyakukennkyuu-Interpreting Studies 1 (1), 8-20.

[13] Gile, D. (2009). Basic concepts and models for interpreter and translator training (Rev. ed.). Amsterdam: John Benjamins.

[14] Gillies, A. (2001). Conference interpreting: A student's companion. Cracow: Tertium.

[15] Gillies, A. (2017). Note-taking for consecutive interpreting: A short course (2nd ed.). London: Routledge.

[16] Gran, L \& Dodds, J. (1989). The theoretical and practical aspects of teaching conference interpretation. Udine: Campanotto.

[17] Ito, H. (2017). Theory and practice of note-taking, cognitive-psychological perspective. InY. Someya Consecutive notetaking and interpreter training. London: Routledge, 29-70.

[18] Ivanova, A. (1999). Discourse processing during simultaneous interpreting: An expertise approach. PhD dissertation, Cambridge University.

[19] Jones, R. (1998). Conference interpreting explained. Manchester: St. Jerome.

[20] Komatsu, T. (2012). Eigo de Hanasu Hinto [How to speak in English fluently: Advice from an interpreter]. Tokyo: Iwanami Shoten.

[21] Komatsu, T. (2017). A brief history of interpreting and interpreter training in Japan since the 1960s. In Y. Someya (Ed.), Consecutive notetaking and interpreter training. London: Routledge, 5-28.

[22] Kroll, J. F. \& Stewart, E. (1994). Category interference in translation and picture naming: Evidence for asymmetric connections between bilingual memory representations. Journal of Memory and Language 33 (2), 149-174.

[23] Matyssek, H. (1989). Handbuch der Notizentechnik für Dolmetcher. Ein Weg zur sprachunabhängigen Notation. Heidelberg: Julius Groos.

[24] Mead, P. (2002). Exploring hesitation in consecutive interpreting: An empirical study. In G. Gazone \& M. Viezzi (Eds.), Interpreting in the 21 st century. Amsterdam/Philadelphia: John Benjamins.73-82

[25] Mead, P. (2011). Co-ordinating delivery in consecutive interpreting. inTRAlinea 13. http://www.intralinea.org/archive/article/Co-ordinating_Delivery_in_Consecutive_Interpreting (accessed 17 May 2018).

[26] Miyake, A. \& Shah, P. (Eds.) (1999). Models of working memory: Mechanism of active maintenance and executive control. New York: Cambridge University Press.

[27] Mukai, G., Maruyama, Y. \& Matsuoka, H. (2004). Tsuuyakushiki gakushuhou de dondon hanaseru dondoneikaiwa. Tokyo: Kennkyusha.

[28] Pöchhacker, F. (2016). Introducing interpreting studies (2nd ed.). London: Routledge.

[29] Rozan, J. F. (1956). La prise de notes en interprétation consecutive [Note-taking in Consecutive Interpreting]. Geneva: Georg.

[30] Russell, D. (2005). Consecutive and simultaneous interpreting. In T. Janzen (Ed.), Topics in signed language interpreting. Amsterdam: John Benjamins, 135-164.

[31] Russell, D. \& Takeda, K. (2015). Consecutive interpreting. In H. Mikkelson \& R. Jourdenais (Eds.), The Routledge handbook of interpreting. London and New York: Routledge, 96-111.

[32] Schweda-Nicholson, N. (1985). English consecutive interpretation training: Videotapes in the classroom. Meta 30 (2), 148-154.

[33] Seleskovitch, D. (1984). Zur Theorie des Dolmetschens. In V. Kapp (Ed.), Übersetzer und Dolmetscher. Munich: Germany 32-50.

[34] Seleskovitch, D. (1988). Der Konferenzdolmetscher: Sprache und Kommunikation. Heidelberg: Julius Groos Verlag.

[35] Seleskovitch, D. (2002). Language and memory: a study of note-taking in consecutive interpreting. In F. Pöchhacker \& M. Shlesinger (Eds.), The interpreting studies reader. London: Routledge, 121-129.

[36] Thiéry, C. (1981). L'enseignement de la prise de notes en interprétation consécutive: Un faux problème? In J. Delisle (Ed.), L'Enseignement de la Traduction et de l'Interprétation. De la Théorie à la Pédagogie. Ottawa: Éditions de l'Université d'Ottawa, 99-112.

[37] Tomono, M., Miyamoto, T. \& Minamitsu, Y. (2012). Tsuuyakugaku 101. Osaka: Osaka Kyouiku Tosho.

[38] Viaggio, S. (1995). The praise of sight translation (and squeezing the last drop thereout of). The Interpreters' Newsletter 6, 33-42.

[39] Yamada, H. (2015). Introduction of written test in evaluation of English-Japanese interpreting classes at universities in Japan. Interpreting and Translation Studies 15, 91-112.

[40] Yamada, H. (2018). Interpreting process analyzed based on the multidirectional reformulation activities of new learners. Theory and Practice in Language Studies 8 (3), 267-277.

Hiroko Yamada is an associate professor at the University of Foreign Language, Kansaigaidai College, Japan. She obtained a master's degree from Ritsumeikan University and a PhD from the Kyoto University. She is interested in the pedagogy of interpreting and has extensive experience with consecutive and simultaneous interpreting. 